\title{
Falla de respuesta anticorpórea frente a antígenos polisacáridos. Serie de casos
} Specific antibody deficiency. Cases serie

\author{
Dra. Diana Cabanillas ${ }^{a}$, Dra. Virginia D’Alessandro ${ }^{b}$ Dra. Graciela Diez y y Dra. Lorena Regairaz ${ }^{a}$
}

\begin{abstract}
RESUMEN
La falla de respuesta anticorpórea frente a antígenos polisacáridos es una inmunodeficiencia primaria humoral definida como una pobre respuesta frente a antígenos polisacáridos contenidos en la vacuna antineumocócica de 23 serotipos, con inmunoglobulinas normales y respuesta adecuada frente a antígenos proteicos. Las manifestaciones clínicas reportadas incluyen infecciones sinopulmonares recurrentes, infecciones sistémicas y asma. El objetivo de esta presentación es describir las manifestaciones clínicas y la evolución en una cohorte de pacientes con falla de respuesta anticorpórea frente a antígenos polisacáridos diagnosticados y seguidos en nuestro centro entre 1998 y 2012.

Palabras clave: inmunodeficiencia, infecciones respiratorias, falla de respuesta frente a polisacáridos.
\end{abstract}

\begin{abstract}
Specific antibody deficiency is a common antibody immunodeficiency defined as a poor antibody response to pneumococcal polysaccharides antigens present in the 23 -valent pneumococcal vaccine, with normal immunoglobulins and normal response to protein antigens. Clinical manifestations include recurrent sinopulmonary infections, severe infections and asthma. The aim of this presentation is to describe clinical manifestations and evolution of a cohort of children with specific antibody deficiency diagnosed and followed in our center between 1998 and 2012.

Keywords:immunodeficiency, respiratory infections, polysaccharide antibody response failure.
\end{abstract}

http:/ /dx.doi.org/10.5546/aap.2014.e247

\section{INTRODUCCIÓN}

La falla de respuesta anticorpórea frente a antígenos polisacáridos (FRPS) es una inmunodeficiencia humoral definida por la inadecuada respuesta del sistema inmunológico frente a antígenos polisacáridos contenidos en la vacuna antineumocócica de 23 serotipos, que ocurre en personas mayores de 2 años de vida. Los pacientes afectados muestran concentraciones

a. Unidad de Inmunología.

b. Servicio de Neumonología.

Hospital de Niños Sor María Ludovica, La Plata.

Correspondencia:

Dra. Lorena Regairaz: loreregairaz@yahoo.com

Conflicto de intereses: ninguno que declarar.

Recibido: 12-8-2013

Aceptado: 4-6-2014 normales de inmunoglobulinas y adecuada respuesta frente a antígenos proteicos. ${ }^{1,2}$

Si bien se presenta más comúnmente en niños, su prevalencia y la totalidad de sus manifestaciones clínicas son poco conocidas; las más frecuentes son las infecciones respiratorias recurrentes. $^{2}$

Este defecto puede ser fisiológico en menores de dos años. Puede presentarse aislado o como parte de otras inmunodeficiencias primarias o secundarias.

El objetivo de este reporte es describir las manifestaciones clínicas y la evolución en una cohorte de pacientes con FRPS diagnosticados y seguidos en nuestro centro entre 1998 y 2012.

\section{POBLACIÓN Y MÉTODOS}

Se seleccionaron los pacientes a los cuales se les diagnosticó FRPS entre los años 1998 y 2012.

Se incluyeron aquellos individuos mayores de 2 años que presentaban infecciones recurrentes, dosaje de IgG, IgA e IgM normal, adecuada respuesta frente a antígenos proteicos (evaluada por anticuerpos antitoxoide tetánico $>0,1 \mathrm{UI} / \mathrm{ml}$ ) y anticuerpos antineumococo inferiores a $113 \mathrm{mg} / \mathrm{dl}$, medidos por ELISA (VaccZyme $^{\mathrm{TM}}$ IgG enzime immunoassay kit), de 4 a 6 semanas luego de la aplicación de la vacuna polisacárida de 23 serotipos. Se excluyeron aquellos niños con otras inmunodeficiencias primarias (deficiencias humorales, deficiencias de complemento, inmunodeficiencias combinadas, inmunodeficiencias sindrómicas, asplenia) o inmunodeficiencias secundarias (infección por VIH).

Se midieron por nefelometría el dosaje de IgG, IgA e IgM y de factores de complemento C3 y C4. La IgE se midió por ELISA. La actividad hemolítica del complemento (CH100) se realizó por inmunodifusión radial. El recuento de leucocitos con fórmula diferencial se determinó por Coulter. Los subtipos linfocitarios se realizaron por citometría de flujo.

Se definió:

Infecciones recurrentes: ocurrencia de 4 o más infecciones en un año. 
Neumonía: infección aguda del parénquima pulmonar con signos clínicos de ocupación alveolar y radiológicos de opacidad, sin pérdida de volumen, de localización única o múltiple.

Bronquitis: tos persistente con secreciones purulentas.

Bronquiectasias: dilataciones bronquiales anormales e irreversibles, demostradas por tomografía axial computada de alta resolución.

\section{RESULTADOS}

De un total de 278 pacientes con deficiencias humorales registrados en la Unidad de Inmunología, catorce (5\%) presentaron diagnóstico de FRPS (Tabla 1). El 60\% (8 pacientes) fueron mujeres. La edad promedio al inicio de las infecciones fue de 3,08 años con un rango de 0,2 a 13 años, mientras que la edad al momento del diagnóstico fue de 8,07 años con un rango de 2,9 a 20 años.

En cuanto a las manifestaciones clínicas, observamos que todos los pacientes tenían antecedente de infecciones recurrentes al momento del diagnóstico. Se constataron 42 eventos de neumonía en once pacientes $(78 \%$ de los pacientes) y 85 eventos de bronquitis en diez pacientes $(71 \%)$.

Las infecciones de piel y partes blandas (impétigo, forunculosis y celulitis) fueron observadas en cinco niños (36\%) y otitis media aguda en tres (21\%). Infecciones invasivas fueron registradas en cuatro niños (28\%): uno de ellos presentó sepsis por Streptococcus spp. y un evento posterior de sepsis por Klebsiella spp., dos niños cursaron sepsis sin aislamiento de germen, y otro niño, a los tres años de vida, presentó una meningitis por Streptococcus pneumoniae. Se destaca que este último estaba inmunizado con vacuna antineumocócica conjugada heptavalente y vacuna polisacárida.

E1 90\% (trece pacientes) presentaron antecedentes de sibilancias recurrentes al momento del diagnóstico y en cuatro de seis estudiados con tomografía axial computada de alta resolución se observaron bronquiectasias.

El valor medio de anticuerpos antineumococo observado en nuestra cohorte fue de $29 \mathrm{mg} / \mathrm{L}$, con un rango de 1,1 a $61 \mathrm{mg} / \mathrm{L}$.

Una vez diagnosticados, doce de catorce pacientes $(86 \%)$ iniciaron tratamiento antibiótico profiláctico (trimetroprima-sulfametoxasol, $5 \mathrm{mg} / \mathrm{kg} /$ día, o amoxicilina, $20 \mathrm{mg} / \mathrm{kg} /$ día), mientras que los dos restantes perdieron el seguimiento. Tres de los doce $(25 \%)$ requirieron la administración de gamaglobulina endovenosa o subcutánea por persistencia de infecciones a pesar de la correcta administración del antibiótico durante, al menos, 6 meses.

El tiempo de seguimiento luego del diagnóstico fue de 3,63 años, con un rango de 0,9 a 13 años.

El número de infecciones/paciente/año disminuyó de 1,29 al momento del diagnóstico a 0,41 una vez iniciado el tratamiento. Las infecciones registradas postratamiento fueron neumonías y bronquitis, y no se constató ningún evento de sepsis ni meningitis.

Todos los pacientes están vivos actualmente, con una edad promedio de 11,7 años con un rango de 3,8 a 33 años.

\section{COMENTARIO}

La FRPS es una inmunodeficiencia primaria humoral que se presenta en niños, jóvenes y adultos con infecciones respiratorias altas y bajas recurrentes, principalmente rinitis, sinusitis crónica y otitis media, seguidos en frecuencia por bronquitis y neumonía. ${ }^{3}$ Son menos frecuentes las infecciones sistémicas, como sepsis y meningitis. ${ }^{1,2}$ Se estima que más del $50 \%$ de los pacientes presentan además asma y rinitis alérgicas.

La etiología de esta inmunodeficiencia primaria (IDP) permanece desconocida en la actualidad, a pesar de los grandes avances en el campo de la biología molecular en inmunología. ${ }^{13}$ Sin embargo, se postula que no sería uno solo el mecanismo patogénico responsable de esta entidad, ya que son diversas las condiciones en las que se observa una falla en la respuesta anticorpórea frente a antígenos polisacáridos. Esto sugiere que múltiples mecanismos inmunológicos llevarían al mismo fenotipo clínico. ${ }^{2}$

Este defecto es fisiológico en menores de dos años, relacionado con la inmadurez natural del sistema inmunológico para responder frente a antígenos polisacáridos.

La falla de respuesta anticorpórea frente a antígenos polisacáridos puede presentarse como parte de otras inmunodeficiencias primarias, tales como el síndrome de Wiskott Aldrich (WAS), deficiencia de $\operatorname{Ig} \mathrm{A}$, síndrome autoinmune con linfroproliferación (ALPS), síndrome de Di George (DGS), síndrome de Hiper IgE (HIES) y deficiencia de NEMO, entre otros. ${ }^{1,13}$ Además, puede encontrarse asociada a inmunodeficiencias secundarias, como asplenia, leucemias y linfomas e infección por VIH..$^{4-7}$ Todas estas entidades deben descartarse en primera instancia frente a un paciente mayor de 2 años con infecciones 
recurrentes, en el que se constata una falla en la respuesta anticorpórea frente a antígenos polisacáridos. Para ello, es necesario realizar un completo interrogatorio y examen físico en busca de signos orientadores de ciertas
IDP, como eczema y petequias en pacientes con WAS, eczema, defectos de línea media y facies peculiar en pacientes con HIES, displasia ectodérmica en pacientes con deficiencias de NEMO, linfoproliferación en pacientes con

TABla 1. Características de los pacientes

\begin{tabular}{|c|c|c|c|c|c|c|c|c|}
\hline $\mathbf{N} \mathbf{S}$ & $\begin{array}{l}\text { Edad de } \\
\text { inicio }^{1}\end{array}$ & $\begin{array}{c}\text { Edad } \\
\mathrm{Dx}^{2}\end{array}$ & $\begin{array}{l}\text { Infecciones } \\
\text { Tipo (número) }\end{array}$ & $\begin{array}{c}\text { Manifestaciones } \\
\text { no infecciosas }\end{array}$ & $\begin{array}{c}\text { Anticuerpos } \\
\text { antineumococo }^{3}\end{array}$ & Tratamiento & $\begin{array}{l}\text { Infecciones pos } \\
\text { diagnóstico } \\
\text { Tipo (número) }\end{array}$ & $\begin{array}{c}\text { Edad } \\
\text { actual }^{4}\end{array}$ \\
\hline $1 \mathrm{~F}$ & 0,8 & 5 & $\begin{array}{l}\text { Neumonía (2) } \\
\text { SPP/shock } \\
\text { séptico (1) }\end{array}$ & $\begin{array}{l}\text { Sibilancias } \\
\text { recurrentes }\end{array}$ & 55 & TMS & - & 6 \\
\hline $2 \mathrm{~F}$ & 3 & 8,4 & $\begin{array}{l}\text { Bronquitis (10) } \\
\text { Neumonía (1) } \\
\text { OMA (1) }\end{array}$ & $\begin{array}{l}\text { Sibilancias } \\
\text { recurrentes }\end{array}$ & 61 & TMS & Bronquitis (1) & 12,7 \\
\hline $3 \mathrm{~F}$ & 3 & 5 & Bronquitis (10) & $\begin{array}{l}\text { Sibilancias } \\
\text { recurrentes }\end{array}$ & 17 & TMS & - & 6,7 \\
\hline $4 \mathrm{M}$ & 13 & 20 & $\begin{array}{l}\text { Bronquitis }(10) \\
\text { Infecciones } \\
\text { cutáneas }\end{array}$ & $\begin{array}{l}\text { Sibilancias } \\
\text { recurrentes } \\
\text { Eczema }\end{array}$ & 46 & TMS & Bronquitis (1) & 33 \\
\hline $5 \mathrm{M}$ & 3 & 9 & $\begin{array}{l}\text { Neumonía (4) } \\
\text { Meningitis } \\
\text { S. pneumoniae } \\
\text { OMA (5) }\end{array}$ & - & 7,6 & Amoxicilina & - & 17 \\
\hline $6 \mathrm{M}$ & 2 & 4,6 & $\begin{array}{c}\text { Neumonía (5) } \\
\text { Infecciones cutáneas }\end{array}$ & $\begin{array}{l}\text { Sibilancias } \\
\text { recurrentes }\end{array}$ & 26 & - & $\begin{array}{l}\text { Bronquitis (2) } \\
\text { Neumonía (2) }\end{array}$ & 6,3 \\
\hline $7 \mathrm{~F}$ & 0,2 & 11,1 & $\begin{array}{l}\text { Bronquitis (10) } \\
\text { Neumonía (7) } \\
\text { OMA (3) }\end{array}$ & $\begin{array}{l}\text { Sibilancias } \\
\text { recurrentes }\end{array}$ & 42 & $\begin{array}{l}\text { Amoxicilina/ } \\
\text { GGEV }\end{array}$ & - & 12,8 \\
\hline $8 \mathrm{M}$ & 2 & 4 & $\begin{array}{l}\text { Bronquitis (10) } \\
\text { Neumonía (3) } \\
\text { Infecciones } \\
\text { cutáneas }\end{array}$ & $\begin{array}{l}\text { Sibilancias } \\
\text { recurrentes }\end{array}$ & 1,1 & - & Bronquitis (2) & 9 \\
\hline $9 \mathrm{M}$ & 0,6 & 9 & $\begin{array}{l}\text { Bronquitis (10) } \\
\text { Neumonía (8) } \\
\text { Sepsis }\end{array}$ & $\begin{array}{l}\text { Sibilancias } \\
\text { recurrentes }\end{array}$ & 61 & TMS & Bronquitis (2) & 10,6 \\
\hline $10 \mathrm{~F}$ & 0,6 & 10,3 & $\begin{array}{c}\text { Bronquitis (7) } \\
\text { Infecciones cutáneas }\end{array}$ & $\begin{array}{l}\text { Sibilancias } \\
\text { recurrentes }\end{array}$ & 24 & TMS & $\begin{array}{l}\text { Bronquitis (1) } \\
\text { Neumonía (3) }\end{array}$ & 13,6 \\
\hline $11 \mathrm{~F}$ & 2 & 2,9 & $\begin{array}{c}\text { Neumonía (4) } \\
\text { Sepsis } \\
\text { Streptoccoccus }(1) \\
\text { Sepsis Klebsiella }(1)\end{array}$ & $\begin{array}{l}\text { Sibilancias } \\
\text { recurrentes } \\
\text { Urticaria }\end{array}$ & 23,6 & TMS & Bronquitis (1) & 3,8 \\
\hline $12 \mathrm{~F}$ & 4 & 4,8 & $\begin{array}{l}\text { Bronquitis (5) } \\
\text { Neumonía (1) }\end{array}$ & $\begin{array}{l}\text { Sibilancias } \\
\text { recurrentes } \\
\text { Cardiopatía }\end{array}$ & 7,3 & TMS & $\begin{array}{l}\text { Bronquitis (2) } \\
\text { Neumonía (1) }\end{array}$ & 10,5 \\
\hline $13 \mathrm{~F}$ & 3 & 10,3 & $\begin{array}{c}\text { Bronquitis (8) } \\
\text { Neumonía (6) } \\
\text { Infecciones cutáneas }\end{array}$ & $\begin{array}{l}\text { Sibilancias } \\
\text { recurrentes }\end{array}$ & 17,9 & TMS/GGSC & Bronquitis (2) & 12,3 \\
\hline $14 \mathrm{M}$ & 1 & 8,6 & $\begin{array}{l}\text { Bronquitis (10) } \\
\text { Neumonía (1) }\end{array}$ & $\begin{array}{l}\text { Sibilancias } \\
\text { recurrentes }\end{array}$ & 20 & TMS/GGEV & Bronquitis (3) & 10,2 \\
\hline
\end{tabular}

Referencias: (1) Edad decimal al inicio de las infecciones. (2) Edad decimal al momento del diagnóstico. (3) Anticuerpos antineumococo totales medidos por ELISA en $\mathrm{mg} / \mathrm{dl}$. (4) Edad decimal al momento del último control.

N: número; S: sexo; F: femenino; M: masculino; SPP: supuración pleuropulmonar; OMA: otitis media aguda; TMS: tretoprimasulfametoxasol; GGEV: gamaglobulina endovenosa; GGSC: gamaglobulina subcutánea. 
ALPS, facies peculiar, cardiopatía congénita y antecedente de hipocalcemia en pacientes con DGS. Esto, sumado a métodos complementarios generales (hemograma, ERS, serología VIH) y específicos (dosaje de IgG, IgA, IgM, IgE, respuesta anticorpórea frente a antígenos proteicos, poblaciones linfocitarias, biología molecular), permite descartar las patologías antes referidas y constatar el diagnóstico de FRPS.

Existen varios métodos de laboratorio para la medición de anticuerpos específicos contra neumococo. La prueba diagnóstica por excelencia para esta entidad es el test ELISA de tercera generación, que mide anticuerpos IgG antineumococo, y puede diferenciar la respuesta frente a diferentes serotipos contenidos en la vacuna neumocócica polisacárida. ${ }^{8}$ En la mayoría de las instituciones de nuestro país, disponemos de un test ELISA que mide IgG antineumococo total, técnica también utilizada. Se consideran protectores títulos de anticuerpos antineumococo superiores a $113 \mathrm{mg} / \mathrm{L}$ medidos entre 4 y 6 semanas luego de aplicada la vacuna. Valores menores de $30 \mathrm{mg} / \mathrm{L}$ se consideran respuesta ausente, mientras que títulos intermedios (entre 30 y $113 \mathrm{mg} / \mathrm{L}$ ) ameritarían medir anticuerpos específicos contra los diferentes serotipos contenidos en la vacuna. Sin embargo, debido a la dificultad en la accesibilidad a esta técnica, las decisiones terapéuticas en estos pacientes se toman de forma individual sobre la base de la gravedad de las manifestaciones clínicas.

En este artículo, presentamos una cohorte de pacientes con infecciones recurrentes, evaluados en nuestra unidad con sospecha de inmunodeficiencia humoral, en los que se diagnosticó FRPS.

Las infecciones más frecuentemente observadas en nuestra cohorte fueron bronquitis purulentas y neumonías, a diferencia de lo descrito en la literatura, en la que predominan otitis media aguda, otitis crónica y sinusitis como principales infecciones asociadas a esta inmunodeficiencia. ${ }^{9,10}$

Las sibilancias recurrentes, también fuertemente asociadas a la FRPS en los casos reportados, se presentaron en nuestra cohorte con alta frecuencia ( $90 \%$ de los niños, al momento del diagnóstico). ${ }^{2,3}$

La presencia de bronquiectasias fue observada en el $66 \%$ de los pacientes estudiados. Esta es una de las consecuencias de las infecciones pulmonares recurrentes en pacientes con ciertas inmunodeficiencias primarias y generalmente se desarrollan antes del diagnóstico, como consecuencia de su retraso. ${ }^{12,14}$

El tratamiento de esta entidad tiene como objetivo disminuir el número y la gravedad de las infecciones para mejorar la calidad de vida de los pacientes afectados y prevenir complicaciones, como la pérdida auditiva o las bronquiectasias. Las opciones recomendadas en la actualidad incluyen el uso profiláctico de antibióticos de forma prolongada. ${ }^{2}$ Los más usados en nuestro medio son amoxicilina o trimetoprima sulfametoxasol en dosis profiláctica. ${ }^{14} \mathrm{Si}$, a pesar de buena adherencia al tratamiento con antibióticos, se constata persistencia de infecciones, se recomienda el uso de gamaglobulina en dosis sustitutiva. En nuestra cohorte, el tratamiento instituido (antibiótico profiláctico y/o gamaglobulina, según el caso) disminuyó el número y la gravedad de las infecciones, lo que coincide con lo previamente descrito. ${ }^{11}$

La FRPS puede ser una inmunodeficiencia transitoria o permanente. Las formas transitorias son más comunes en niños de 2 a 5 años de vida, motivo por el cual, una vez instituido el tratamiento, los pacientes deben ser revalorados entre 1 y 2 años desde su inicio, mediante la aplicación de una nueva dosis de vacuna antineumocócica de 23 serotipos y medición posterior de anticuerpos. En caso de recibir gamaglobulina, la revacunación y posterior evaluación de la respuesta anticorpórea deberá realizarse luego de 4 a 6 meses de suspendida. ${ }^{2}$ Además, se recomienda monitorear periódicamente (una vez al año) el dosaje de inmunoglobulinas ya que se han reportado pacientes con FRPS que en la evolución muestran hipogamaglobulinemia. ${ }^{2}$

Todos los pacientes de nuestra cohorte que iniciaron tratamiento se encuentran en seguimiento actualmente en nuestra unidad. Ninguno de ellos corrigió el defecto ni evolucionó a hipogamaglobulinemia. Sin embargo, se trata de una muestra pequeña con un tiempo de seguimiento relativamente corto $(3,63$ años en promedio) para arribar a conclusiones válidas en este aspecto.

\section{CONCLUSIÓN}

La FRPS debería ser sospechada por el pediatra en aquellos niños mayores de 2 años con infecciones respiratorias recidivantes, asociadas o no a sibilancias recurrentes, cuando el dosaje de inmunoglobulinas presenta resultados normales. 
La derivación oportuna al especialista y el inicio precoz del tratamiento mejora la calidad de vida de los niños afectados.

\section{REFERENCIAS}

1. Stiehm ER, Ochs HD, Winkelstein J. Antibody deficiencies. En: Immunologic disorders in infants and children. $5^{\text {th }}$ ed. Philadelphia: Elsevier Saunders; 2004.Págs.356-425.

2. Metodiev K, ed. Immunodeficiency. Rijeka, Croatia: En: Tech; 2012. Chapter 8, Selective antibody deficiency with normal immunoglobulins. Disponible en: http://www. intechopen.com/books/immunodeficiency/selective-antibody-deficiency-with-normal-immunoglobulins. [Consuta: 4 de junio de 2014].

3. Cheng YK, Decker PA, O`Byrne MM, Weiler CR. Clinical and laboratory characteristics of 75 patients with specific polysaccharide antibody deficiency syndrome. Ann Allergy Asthma Immunol 2006;97(3):306-11.

4. Durandy A, Kracker S, Fischer A. Primary antibody deficiencies. Nat Rev Immunol 2013;13(7):519-33.

5. Boyle RJ, Le C, Balloch A, Tang, ML. The clinical syndrome of specific antibody deficiency in children. Clin Exp Immunol 2006;146(3):486-92.

6. Molrine DC, Siber GR, Samra Y, Shevy DS, et al. Normal IgG and impaired IgM responses to polysaccharide vaccines in asplenic patients. J Infect Dis 1999;179(2):513-7.

7. Siber GR, Weitzman SA, Aisenberg AC, Weinstein HJ, et al. Impaired antibody response to pneumococcal vaccine after treatment for Hodgkin's disease. $N$ Engl J Med 1978;299(9):442-8.

8. Ballet JJ, Sulcebe G, Couderc LJ, Danon F, et al. Impaired anti-pneumococcal antibody response in patients with AIDS-related persistent generalized lymphadenopathy. Clin Exp Immunol 1987;68(3):479-87.

9. Jeurissen A, Moens L, Raes M, Wuyts G, et al. Laboratory diagnosis of specific antibody deficiency to pneumococcal capsular polysaccharide antigens. Clin Chem 2007;53(3):505-10.

10. Cheng YK, Decker PA, O'Byrne MM, Weiler CR. Clinical and laboratory characteristics of 75 patients with specific polysaccharide antibody deficiency syndrome. Ann Allergy Asthma Immunol 2006;97(3):306-11.

11. Ruuskanen O, Nurkka A, Helminen M, Viljanen MK, et al. Specific antibody deficiency in children with recurrent respiratory infections: a controlled study with follow-up. Clin Exp Immunol 2013;172(2):238-44.

12. Kim HY, Know JW, Seo J, Song YH, et al. Bronchiectasis in children: 10-year experience at a single institution. Allergy Asthma Immunol Res 2011;3(1):39-45.

13. Kuruvilla M, de la Morena MT. Antibiotic prophylaxis in primary immune deficiency disorders. J Allergy Clin Immunol Pract 2013;1(6):573-82.

14. Paris K, Sorensen RU. Assessment and clinical interpretation of polysaccharide antibody responses. Ann Allergy Asthma Immunol 2007;99(5):462-4. 